\title{
Sustainable Hospitality Management and Dimensions of Environmental Regulations: A Qualitative Study on the Puducherry Perspective
}

Anu Chandran $\mathrm{R} \mathrm{C}^{*}$ and Sherry Abraham ${ }^{\dagger}$

\section{Abstract}

Tourism and hospitality, globally, is experiencing a paradigm shift. The modern day tourists and clients of hospitality are very discerning and opt for higher quality and value based products and services. To cater to their needs, a wide range of properties at various scales are being introduced in the sector. At the same time, it is increasingly recognised that unplanned and uncontrolled hospitality ventures are causing certain adverse impacts on the environment. These necessitate thorough supervision of the hospitality projects, both existing as well as upcoming, and positively check whether they are abiding by the prescribed guidelines as prevailing under the environmental notifications. That is, the set up and operations must be actively monitored as per the Environmental Laws and Rules. The accelerated growth of international and domestic tourists to Puducherry resulted in the spurt of hospitality establishments across the destination. This growth can be sustained only if the hotels, resorts, restaurants and other hospitality outlets operate by showing profound consideration towards the environment. The business practices in the hospitality sector of Puducherry are undergoing great

Assistant Professor, Department of Tourism Studies, Pondicherry University; anoos_ind@yahoo.co.in

† Assistant Professor, Department of Tourism Studies, Pondicherry University; sherryabrahamm@gmail.com 
transformations, imbibing the latest and the best of things. Technological advancements have also altered traditional patterns and many innovative trends are emerging in the hospitality trade. With the increased impact on the environment owing to large scale establishment and expansion of hospitality projects in Puducherry, comes the need for informed planning and sustainable management as well as education and training for developers, investors, planners, managers and local communities. Owing to this reason, the management of hospitality firms in Puducherry must abide by the Environmental Laws and Rules to prevent haphazard, uncontrolled growth, spatial and land use planning; conforming to strict architectural controls, sewerage facilities and water treatment plants. This paper brings to light the challenges faced by the hospitality industry of Puducherry with regards to consumption and conservation of natural resources, by gathering and analysing the opinion of experts from the hospitality trade and the environmental pollution control organisations. This study elucidates the Environmental Laws and Rules which are necessary, as in the case of the hospitality industry of Puducherry, to curtail adverse effects on the environment. It is for sure that, in the future, quality practices and management styles as guided and enforced by the environmental laws would contribute to resolve many shortcomings faced by the hospitality enterprises in Puducherry.

Keywords: Hospitality management; Environmental laws; Sustainability; Preservation; Evaluation; Monitoring.

\section{Introduction}

The importance of conserving and protecting the environment is increasing in this age of global warming and doomsday tourism. In the present day, both the state and the citizens are required to protect and nurture the environment.

The globalisation and liberalisation of the economy, makes it imperative that India must increase its vigil to ensure that its industrial growth does not progress at the cost of the environment. Natural resources are indeed priceless and need to be preserved, 
nourished and well-managed. In its broadest definition, environment refers to all the surroundings or milieu of people. Environment refers to the physical environment, which is comprised of natural and built components. The natural environment is what exists in nature; climate and weather, water features, topography and soil, geology, flora and fauna, etc. The built environment is comprised of man-made physical features; mainly all types of buildings, other structures, and infrastructural development. The relationship between the physical environment and hospitality is a very close one. There has been much concern justifiably expressed in recent years about the undesirable environmental impact from unplanned and uncontrolled management of the hospitality industry in India. Considerable research has been accomplished during the past quarter century on the environmental impacts of hospitality development. So, it is now possible to systematically evaluate these impacts and recommend ways to mitigate them, preferably through preventive measures of environmental planning and engineering. The need of the hour as regards hospitality management in India is the incorporation and imbibing of sustainable practices. It could be interpreted as development which the environment can sustain, which does not exceed the carrying capacity of the environment, and which does not over-exploit or destroy the natural resource base. Concrete and comprehensive Environmental Impact Assessment (EIA) and other feasibility studies are carried out before setting up any hospitality project in India. The hospitality industry in the country is on the fast-track of development. This booming industry is also being identified as a thrust area of infrastructure and economic surge. Yet, there are certain problems such as environmental degradation, high level of air, water and land pollution, etc. These problems can be addressed and solved with the aid of specific laws that have been formulated for this purpose. India has excellent laws to preserve and protect the environment. What is needed is political will power and good governance for its proper implementation (Nagore,1996). Over the years there has been considerable growth in the sphere of environmental law. Environmental Tribunals, Green Benches and a National Environmental Appellate Authority have been constituted, which is a path breaking development. Environmental Impact Assessment and Environmental Statement 
are important developments to control pollution (Leela Krishnan. P., 1999).

\section{Objectives of the Study}

- To outline and discuss the major environmental laws and rules that is of utmost significance for the establishment and operation of hospitality industry in Puducherry.

- To elucidate the eco-sensitive aspects of hospitality management in Puducherry.

- To identify the gap areas with regard to the environmental considerations in planning, in the hospitality industry of Puducherry and their effective implementation.

\section{Scope of the Study}

In recent times, several environmental problems have come to be recognised in the hospitality industry. Several environmentalists as well as major players of the hospitality trade in Puducherry are demanding that the environmental issues be addressed properly. With the fast paced growth of hospitality in Puducherrry, in terms of the drastic increase in the number of hotels, resorts, motels and other forms of supplementary accommodation, there is a lot of pressure on the natural resources. To address these environmental issues in their proper perspectives, a comprehensive knowledge of the Environmental Laws and Rules and its efficiency in regulation, evaluation and monitoring is a dire necessity. In this connection, there is ample scope for a qualitative study on the impact of Environmental laws on the establishment and operations of the hospitality industry in Puducherrry. Moreover, the scope of this study covers the need for building a concrete theoretical base for chalking out prospective guidelines by recommending a model for problem solving.

\section{Data Collection}

Both primary and secondary data were used for this study. Expert opinion was gathered from managerial staff of hotels, resorts and 
restaurants of Puducherry and officials of Municipality, Town planning and Pollution Control Board. Secondary data was collected from websites, magazines, books and Law Journals.

In-depth interviews and Focus Group interviews were employed to gather data. Post review of media information and other relevant literature, questions to draw data to substantiate the objectives were framed. The content analysis method was chosen to infer from the responses. Also, the responses from the experts were featured as models for comprehensive understanding. Inputs for the questions were chosen from the book Hotel Housekeeping Operations and Management authored by Raghubalan G., Smritee Raghubalan (2010).

\section{Profile of Hospitality Sector in Puducherry}

The hospitality sector in Puducherrry has undergone substantial changes in recent years. New developments in tourism and transportation, evolving trends in trade and commerce, technological innovations and lifestyle changes are some of the factors which are responsible for these changes. In addition, the paradigm shift among hospitality customers and improvement in living standards and economic conditions have also changed the profile of Puducherry's hospitality sector. All the above factors have certainly influenced the structure of the hospitality industry as a whole. The tendency among budget tourists, up-market clientele and visitors from nearby towns and cities such as Madurai, Trichy, Coimbatore, Bangaluru, Chennai, Cochin, Vellore, etc., to take a holiday at any time of the year has encouraged hospitality operators to offer novel attributes like boutique hotels, service apartments, business hotels, time- share properties, heritage hotels, and eco- friendly resorts. This is in addition to traditional hotel accommodations. Furthermore, the foreign tourists' influx to Puducherry is evenly poised, irrespective of seasonal factors and is found to be constantly on the rise. The spiritual radiance of Puducherry, owing to the presence of the Aurobindo Ashram and the Auroville attracts visitors from all parts of the globe. To cater to the accommodation requirements of the ever escalating foreign and domestic tourists, Puducherry has opened up to setting up Villas too. 
Hospitality industry in Puducherry is a dynamic and gracious concept that encompasses the presentation, effective treatment of guests, ethical responsibilities, portrayal of cultural symbols, high tolerance and acceptance; all these factors ensure the visitors' comfortable stay and wholesome enjoyment. The guests are now looking forward to cost effective service components and value additions.

The hospitality industry of Puducherry configures premier hotels (includes business hotels, budget hotels, and boutique hotels), inns, villas, resorts (includes beach resorts, eco- resorts and health resorts), multi- cuisine restaurants, theme restaurants, sophisticated bars, pubs, traditional restaurants, ethnic restaurants, wayside eating outlets, dhabas, outdoor catering establishments, and convention halls.

\section{Environmental Regulations of Concern to Hospitality Industry}

The terms "environment", "environmental pollutant", "environmental pollution" and "hazardous substances" are defined under the Environment Protection Act, 1986. According to section 2 of E.P.A.,

a) "Environment" includes water, air, land and the relationship that exists among water, air, land, human beings, plants, micro organism, other living creatures, and various kinds of properties.

b) "Environmental pollutant" means any solid, liquid or gaseous substance present in such concentration that maybe or tends to be, injurious to the environment.

c) "Environmental pollution" means the presence in the environment of any environmental pollutant.

"Hazardous Substances" means any substances or preparation which, by reason of its chemical or physico-chemical properties or handling, is liable to cause harm to human beings, other living creatures, plants, micro organisms, property or the environment. 
In the hospitality industry, many non- bio degradable solid waste materials are known to cause considerable environmental hazards, when released into land, water and atmosphere. In exercise of the powers conferred by clause (viii) of sub - section (2) of section 3, read with section 25 of the Environment (Protection) Act, 1986, the Central Government notifies the rules for the manufacture and use of recycled plastic carry bags and containers. As per the Rules, "Foodstuffs" means ready- to- eat food and food products, fast food, processed and cooked food in liquid, powder, solid or semi solid form and "Vendor" means the person who sells food stuffs as defined above - packaged and stored in plastic carry bags and containers. The prescribed authority for the enforcement of the provisions of these rules related to manufacture and recycling, shall be the State Pollution Control Boards with respect to the States and the Pollution Control Committees with respect to the Union Territories.

Some Important Notifications and Rules under the Environment (Protection) Act, 1986 are:

- Hazardous Wastes (Management and Handling) Rules, 1989

- Coastal Regulation Zone Notification, 1991.

- Forest Conservation Act,1980

- Scheme of Labelling of Environment Friendly Products (Ecomarks),1992

- Notification on Environmental Impact Assessment, 1994

- Recycled Plastics Manufacture and Usage Rules,1999

- Noise Pollution (Regulation and Control) Rules, 2000

- Air Act, 1981 (Air pollution means the presence in the atmosphere of any air pollutant)

- Noise Regulation Rules, 2000 (The rules regulate the noise levels in industrial [75 decibels], commercial [65 decibels], and residential zones [ 55 decibels], and also establish zones of silence [100 meters] near schools, courts, hospitals, etc.)

- Water (Prevention and Control of Pollution) Act, 1974. 
“Water Pollution" means

- Contamination of water

- Alteration of the physical, chemical or biological properties of water

- Discharge of any sewage or stared effluent or any other liquid, gaseous or solid substance into water (whether directly or indirectly) which may, or is likely to create a nuisance or render such water harmful or injurious to public health or safety or to domestic, commercial, industrial, or agricultural or other legitimate uses, or to the life and health of animals or plants or of aquatic organisms [Section $2(\mathrm{e})]$.

\section{Focus Areas of Environmental Considerations in Hospitality Management of Puducherry-Content Analysis and Discussions}

The hospitality industry can generate both positive and negative environmental impacts and non appreciable impacts, depending on how its development is planned and controlled. The most commonly accepted types of impacts deliberated by hospitality managers of Pondicherry are mainly dealt with.

The scale of hospitality development in relation to the carrying or absorbing capacity of the environment greatly influences the extent of environmental impacts. In the context of water pollution, if a proper sewage disposal system is not installed in the hotels, resorts or other tourist facilities in Puducherry, it may result in the pollution of the ground water from the sewage, or if a sewage out fall has been constructed into a nearby river or coastal water area, and the sewage has not been properly treated, then the effluent will pollute that water area. This is not an uncommon situation in Destination Puducherry where beach resorts are aplenty. The fact of the matter is that when the out fall is constructed into adjacent water area which may be used by the tourists for swimming, they are exposed to skin diseases.

Puducherry remains humid and sultry during most parts of the year. Hence the use of air conditioners in hotels and resorts is 
relatively more, resulting in excessive emission levels of carbon into the atmosphere causing air pollution.

Poorly designed hotels, restaurants, resorts and other tourist facility buildings, which are not compatible with the local architectural style or scale, use of unsuitable building materials on external surfaces, badly planned layout of tourist facilities, inadequate or inappropriate landscaping, use of large and ugly advertising signs and poor maintenance of hotel buildings and landscaping can result in visual pollution. Littering of the hotel premises also results in visual pollution.

Improper disposal of solid waste from resorts and hotels of Puducherry can generate extreme health problems. As hospitality industry is the biggest user of plastic cups, trays and foils in Puducherry, proper solid waste management system certainly needs to be in place.

Setting up new industries and expansion of the existing industries, except those directly related to the water front or directly needing foreshore facilities are declared as prohibited within the Coastal Regulation Zone. According to the CRZ Notification 1991, the coastal stretches of seas, bays, estuaries, creeks, rivers and backwaters which are influenced by tidal action (in the landward side) up to 500mts from the High Tide Line (HTL) and the land between the Low Tide Line (LTL) and the HTL are called Coastal Regulation Zones (CRZ). Destination Puducherry faces regulations for the development of beach resorts or hotels in the CRZ. Yet, construction of beach resorts or hotels in the designated areas of CRZ-III for temporary occupation of tourists/visitors shall be made with prior approval of the Ministry of Environment and Forests, subject to conditions provided in the Annexure-II of CRZ Notification. However, in ecologically sensitive areas (such as marine parks, mangroves breeding and spawning grounds of fishes and such other areas as may be notified by the Central/State Government/Union Territories), the constructions are not permitted. Destination Puducherry is confronted with many food laws pertaining to various foods, which are more complex in nature, resulting in its difficultly in implementation, maintenance and evolution. This need is being addressed by establishing a new Act - Food Safety and Standards Act, 2006, which is implemented 
across the country. Many tourist organizations and tour operators are insisting on Hazard Analysis and Critical Control Points (HACCP) for sending their clients to the hotels in Puducherry. HACCP is a science - based pro active quality management system, established to guarantee product safety. This is the best available food safety system. The hospitality industry in Puducherry should view the regulators and regulatory agencies as partners for their progress in ensuring food safety.

The managers of hospitality establishments in Puducherry are concerned with the provision of a safe, secure and aesthetic environment conducive to work for the staff and for relaxation of the guests. Among others, the most important consideration in providing an ideal internal environment is maintaining optimum levels of three factors - noise, air conditioning and light. In many hotels, acoustic materials are used in recreation rooms, convention halls, banquet halls, and audio - visual centres. Uncontrolled noise emanating from them can adversely affect both the guests and employees.

The prospective hotel projects should be designed and constructed keeping in mind maximum energy conservation. It is ideal to evaluate the effective conservation of water in all departments of the hotel. The extent to which water is recycled and re- utilised is also an important factor. Also, it is very important that the hospitality industry demonstrates the existence of a formalized commitment towards the preservation and enhancement of the natural environment (Environment Manual for Hotels and Restaurants in India, (2003) FHRAI Report). . It must, through all its functions, activities and written statements, communicate its commitment to the environment. The hotels, resorts, and restaurants in Puducherry must have training modules in place for staff at all levels for familiarising them with the eco- friendly initiatives. The hospitality management must subscribe to newer practices such as rain water harvesting. 


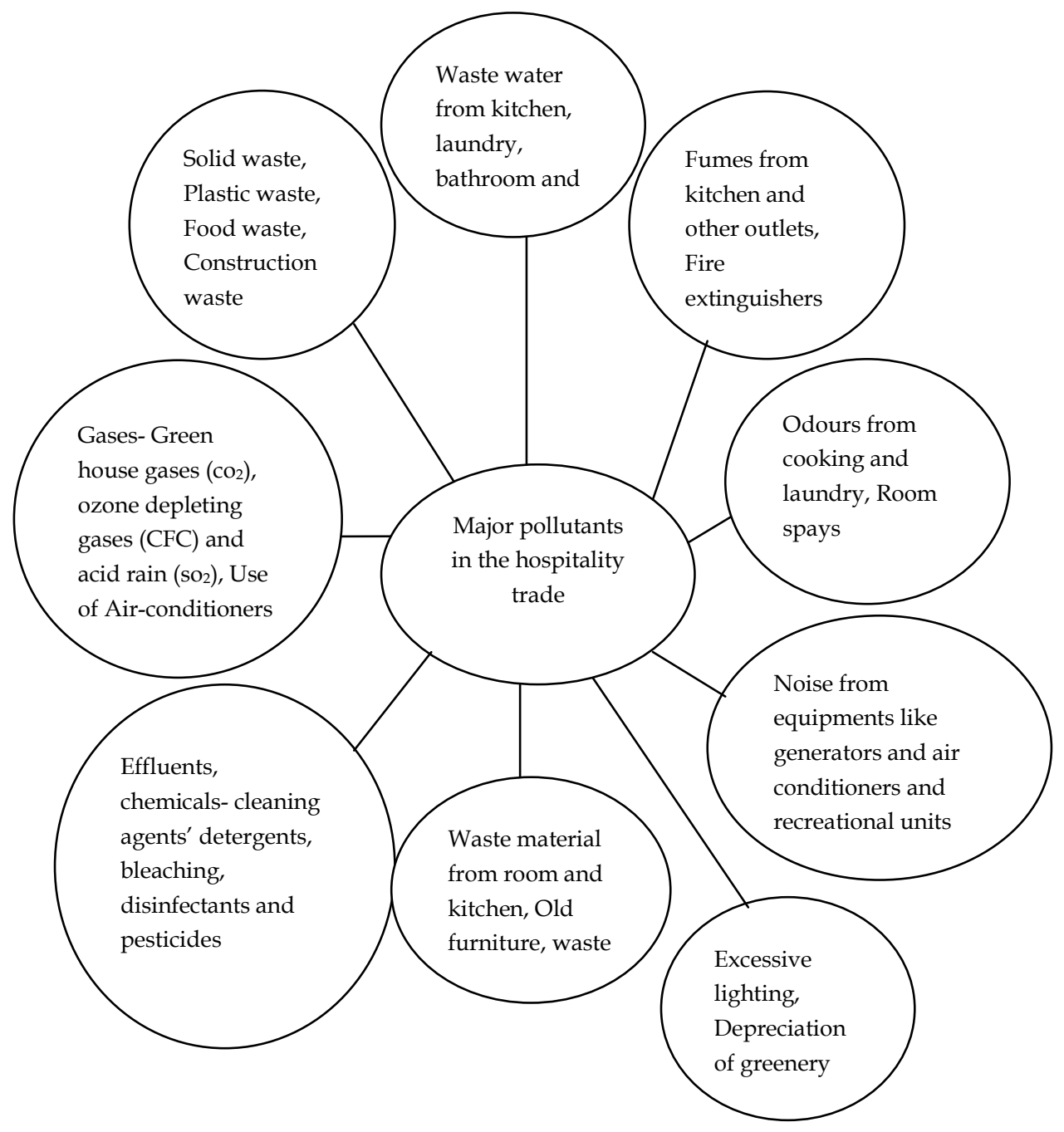

Fig.1: Major Pollutants in the Hospitality Trade:

Environmental management has become an important aspect in the Puducherry hospitality industry, with a number of hotels and resorts adopting excellent environmental management practices in response to the growing concerns for suitable and quality hospitality products. (Negi, 2001).

. The accentuating adoption of environmental management in hospitality firms seems to have been sparked off by growing concerns over the impacts of hospitality on the environment. 
Identifying opportunities for cost savings and improved environmental management is best achieved through an all encompassing and step- by- step process that addresses all aspects of hospitality management and amenities. There are certain hotels and resorts in Puducherry, that have taken steps to recycle and reduce the consumption of energy, thereby reducing costs, increasing profits, and taking some definite steps towards sustainability. Recycling policies in the hospitality industry must be brought under the purview of the environmental law.

Almost every aspect of hospitality, such as catering and hotel business is covered by legislation. Some of the environmental legislations will need to be taken into account at the planning stage. Certain legislations are extremely complicated and may require the advice from legal experts. In Puducherry, investors of hotel projects take counsel of established consultants before submitting their proposal. The main thrust of the environmental laws pertaining to the hospitality industry in Puducherry is to govern the land -use principles, pollution control, and solid waste management, aesthetic structure of buildings, energy use, positive checks on sand mining and CRZ, and water use. Definitive and appropriate Environmental Laws are in place to assess, evaluate and clear the existing properties which opt for expansion. Also, the rules are stringent and at the same time transparent with regard to sanctioning new projects.

The hospitality industry in Puducherry faces acute space constraint that deters organisations from effective environmental management. Hence, to operate from a small area catering to the ever increasing clients by mitigating negative environmental impacts is indeed a difficult process. At the same time, for the sustainable management of hospitality establishments in Puducherry the enforcing authorities should sensitise proprietors and management with regard to the Environmental Laws and Rules as applicable on a case by case basis. 


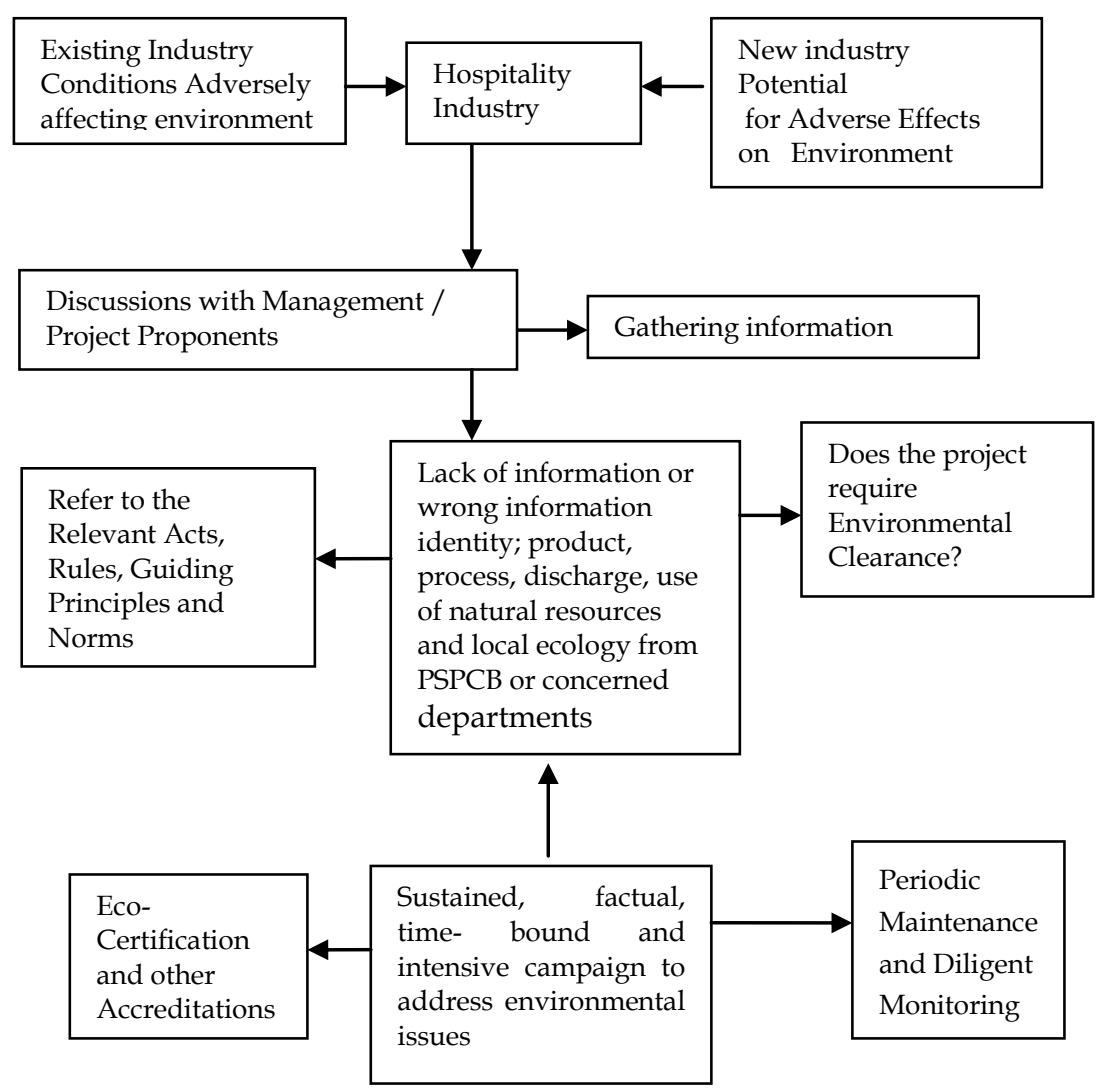

Fig. 2: Proposed Problem Solving Model (To Offset the Adverse Environmental Impacts of Hospitality Management in Puducherry)

\section{Findings of the Study}

- Ignorance of Environmental Laws and Rules among many a hospitality management in Puducherry is a matter of grave concern.

- The documentation of key policies relating to the protection of environment, pertaining to hospitality management will facilitate management control of environmental protection.

- Puducherry has few eco- resorts and it does not have an ecotel. 
- Depreciation of invaluable forest cover to set up hospitality establishments and residential buildings and apartments are not effectively regulated.

- Beach resorts of Puducherry play a significant role in maintaining private beach areas and keeping it pristine and clean.

- There is a lackadaisical approach among authorities in checking whether the hotels, resorts and restaurants are complying with the provision of the environmental rules.

- Even though modern environmental law provides for a system of regulation by statute, administrative agencies created under environmental statutes are required to implement legislative mandates.

- A genuine mechanism is not in place to address threats to marine life from the hospitality ventures in the coastal zone.

- Some of the beach resorts in Puducherry are found to be causing visual pollution, owing to the mismatch in architectural styles that do not blend well with the local features. The design and construction of buildings are found to be inconsistent with the surrounding landscape and the local architectural style.

- Lack of staff, money or other resources, results in the agencies failure, in implementing the laws under which they operate, and because of this, pollution continues unabated.

- Political will power and good governance are dire necessities in regulating adverse environmental practices of the hospitality industry.

- The energy conservation mechanisms not only help the hotel, but also the society and the nation as a whole.

- The use of natural resources (e.g. water, energy, materials, chemicals, etc.) produces the main environmental impacts of the hospitality industry in Puducherry. 
- The hospitality management demonstrate the existence of a formalized commitment towards the preservation and enhancement of the environment.

\section{Suggestions}

- EIA must be made mandatory for all hospitality establishments in Puducherry, keeping in view the landscape and environmental attributes of the destination.

- Hospitality managers need to plan a comprehensive programme for the prevention, control or abatement of air pollution. They must collect and disseminate information related to air pollution. Also, they have to inspect at all times, any control equipment, and give directions to take steps for the prevention, control or abatement of air pollution.

- Periodic check of waste handling mechanism is very important.

- Sewage outlets must not be channelized to the beaches, and water bodies used to supply drinking water. Waste water management technique needs to be refined to channelize the water either to the garden or flush.

- Hospitality concerns in Puducherry must maintain the "safe noise level".

- Proprietors of the hospitality trade need to follow the guidelines for recycling of plastics. They must abide by the rules and popularise the use of jute and paper.

- Prescribed guidelines and effective coaching must be provided to operators of wayside amenities and micro enterprises in hospitality trade directed at educating them towards maintaining the physical evidence of their area of operation.

- Dressing or altering of sand dunes, natural features including landscape changes for beautification, recreational and other such purposes should be permissible under CRZ notification. 
- National Environmental Appellate Authority, Environmental Tribunal and Green Benches have a proactive role to play in positively checking the environmental impacts of the hospitality industry.

- The hospitality industry in Puducherry must be provided with opportunities for public hearings in the matter of environmental clearance.

- The hospitality management must develop an attitude of concern for the environment.

- Expansion of hotel projects must adhere to the carrying capacity.

- Environment audit must be made mandatory for all hospitality projects in Puducherry

- Indicators of sustainability for the hospitality industry should include indexes of the consumption of the resources

- Awareness campaigns regarding conservation of natural resources must be holistic in configuring the tourists and the clients.

- The hospitality ventures could seek certification of its environment management systems from international agencies.

- The building sites must be carefully chosen for hospitality projects. Choosing eco- friendly sites is of paramount importance

- Monitoring should be sufficiently frequent to enable the hotels to take corrective actions, if there is a significant change in consumption or a large deviation from targeted performance. Water and electricity meters should be checked and the water and electricity consumption should be calculated at pre determined periodicity.

\section{Conclusion}

The environmental considerations must form an integral part of all the hospitality development and must be supplemented by 
mechanisms to see to it that the environmental safeguards proposed by way of notifications and rules are actually implemented, together with periodic and systematic monitoring to assess the effectiveness of such precautions in protecting the environment. The traditional concept that development and environment are opposed to each other is no longer acceptable. Sustainable development holds the key. The Environmental Laws and Rules of India are framed to provide clear guidelines and enforce a regulatory mechanism to positively check the adverse effects and imbalance on the natural resources (Goel, \& Sharma, 1996).

Being a renowned destination with immense potential, economic progress is essential for Puducherry, and at the same time care has to be taken of the environment. Hospitality industry in Puducherry has a progressive character, which means that, for its development certain ecological sacrifices are deemed necessary. This is while keeping in mind the nature of the environment in Puducherry and its criticality to the community. Abiding by the environmental policies and laws ensures that the future generations are benefitted. For the hospitality industry of Puducherrry to be deemed successful, it has to meet both the goals; environment as well as development. This ethical mix is termed sustainable development. The hospitality industry in Puducherry, in spite of many a lacuna is not in the list of polluting industries. The need of the hour is for the hospitality management to strive to attain harmony with nature. For this, the hospitality industry needs to ensure compliance with environmental laws and regulations.

\section{References}

Environment manual for hotels and restaurants in India. (2003). FHRAI Report.

Environmental laws of India: An introduction. (2006). Chennai: P. R. Environnemental Education Centre.

Environmental laws of India: An introduction. (2006). Chennai: P. R. Environnemental Education Centre.

Goel, P. K., \& Sharma. K. P. (1996). Environmental guidelines and standards in India. Jaipur: Techno Science Publications. 
Leelakrishnan, P. (1999). Environmental law in India. London: Butterworth.

Nagore, A. P., (1996). Biological diversity and international environmental law. New Delhi: A. P. H. Publishing Corporation.

Negi, J. (2001). Hotel and tourism laws. New Delhi: Frank Bros.

Raghubalan, G., \& Raghubalan, S. (2010). Hotel housekeeping operations and management. New Delhi: Oxford University Press. 